\title{
FIBROMYXOSARCOMA OF THE ORBIT* RADIATION-INDUCED TUMOUR 33 YEARS AFTER TREATMENT OF "BILATERAL OCULAR GLIOMA"
}

\author{
BY \\ PAUL STRICKLAND \\ Consultant Radiotherapist, Mount Vernon Hospital, Northwood, Middlesex
}

RADIATION-INDUCED malignant tumours are being increasingly reported. This paper records an instance of soft-tissue sarcoma of the orbit due, almost certainly, to the successful treatment by radium of a retinoblastoma of the retina 33 years earlier.

\section{Case Report}

In 1931, the patient, then 15 months old, was brought to see Mr. R. Affleck Greeves with a swelling of the right eye of a few weeks' duration. The patient was a full-term male child; the mother's pregnancy had been normal and there were two older siblings, both normal. There was no history of eye trouble in the family.

Three weeks before his attendance the patient had had his left eye removed. It was impossible to find out precise details of this, but at the age of 4 months some abnormality had appeared in the left eye and progressively disorganized it. Enucleation eventually followed. The parents had unusual religious beliefs which constantly intervened between their doctors and the care of the unfortunate child.

On first examination the right eye seemed almost blind. Under anaesthesia two masses of tumour could be seen, one at the side of the disc and one above it. Radium was applied to the right eye-twenty $1.5 \mathrm{mg}$. needles and eight $2.5 \mathrm{mg}$. needles on a columbia paste mould, as was standard practice at the time. The applicator was removed 5 days later, and the procedure repeated 2 weeks afterwards.

Careful observation during the next three months showed no tumour regression; in fact, a new tumour nodule appeared to the nasal side of the disc. Further radium application was carried out; on this occasion $157 \mathrm{mg}$. were used and left in situ for 88 hours.

Shortly after this the tumour appeared flatter but there was a marked radium reaction on the right side of the face associated with epilation of the right side of the scalp. It was not possible to continue observation because the parents removed the child from hospital against advice.

For many years he disappeared from sight, but in 1946-15 years after treatment-his doctor reported that he was alive and well and attending a special school. Shortly afterwards he got a job at a factory bench, where the small amount of vision in the right eye was unimportant, and he remained well, and usefully employed, for 17 years thereafter. He was never formally examined by his own medical practitioner, because of the family's strong aversion to orthodox medical practice.

\footnotetext{
* Received for publication February 9, 1965.
} 
In the autumn of 1963 a lump developed on the right eye. A course of Christian Science therapy was started, but despite this the lump increased steadily in size, and three weeks before he came under my care, his general practitioner had been called in because the patient had been found unconscious at home. I saw him for the first time in September, 1964, 33 years after the original radium treatment to the right eye.

There was a mass measuring $10 \times 7 \mathrm{~cm}$. and raised $7 \mathrm{~cm}$. above the skin, totally replacing the right orbit, filling the temporal fossa and replacing much of the right side of the face. The surface of the mass was smooth, firm, semifluctuant, and mauve-red in colour; it was not particularly warm. The left orbit was empty (Figs 1 and 2). There were no other abnormal physical signs elsewhere in the body.

A diagnosis of radiation-induced soft-tissue sarcoma was made; recurrent retinoblastoma was thought to be only remotely possible.

\section{Course of the Illness}

For a few days the intellect remained unclouded, but periods of increasingly deep drowsiness developed and it was clear that the patient would not survive. Three large biopsies were taken from the mass on different days, but the pathologist reported chronic inflammatory tissue only with no sign of malignancy.

Lumbar puncture produced a clear colourless fluid at $190 \mathrm{~mm}$. pressure with a free rise and fall. The fluid contained $140 \mathrm{mg}$. protein per $100 \mathrm{ml}$., but all other constituents were normal. Blood analysis, chest $x$-ray, and $x$-ray of the skull were all normal.

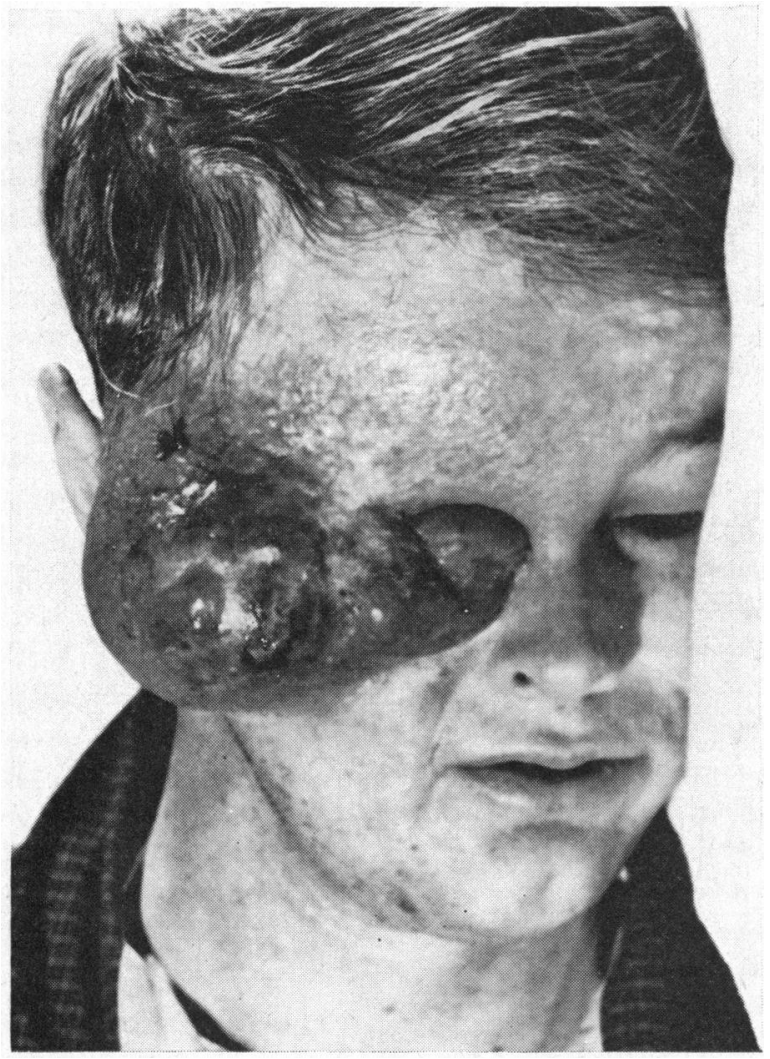

FIG. 1.-Showing the extent of the tumour medially and radiation-damaged skin on forehead.

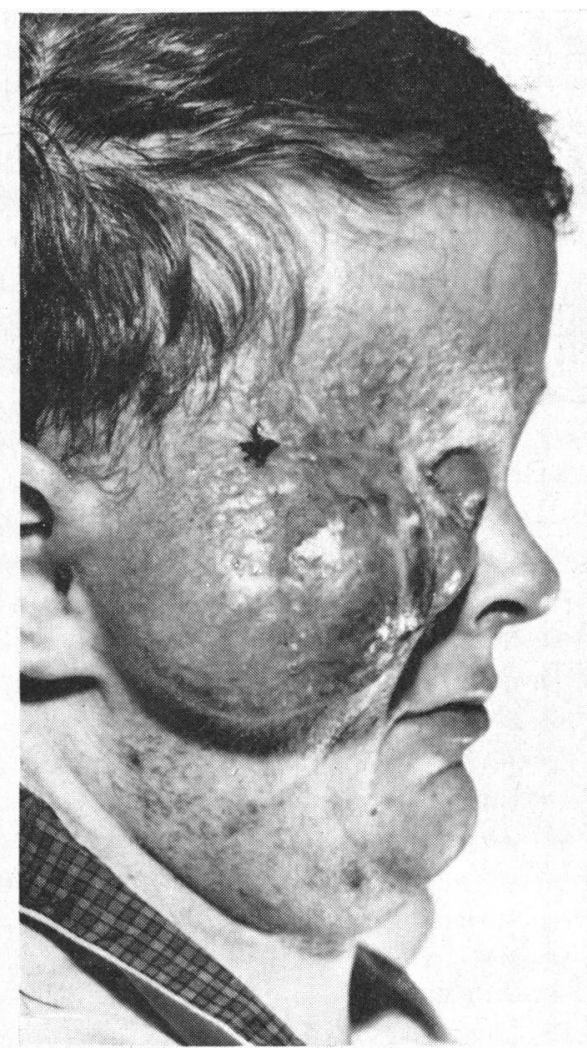

Fig. 2.- Showing extent of outward spread of the tumour. 


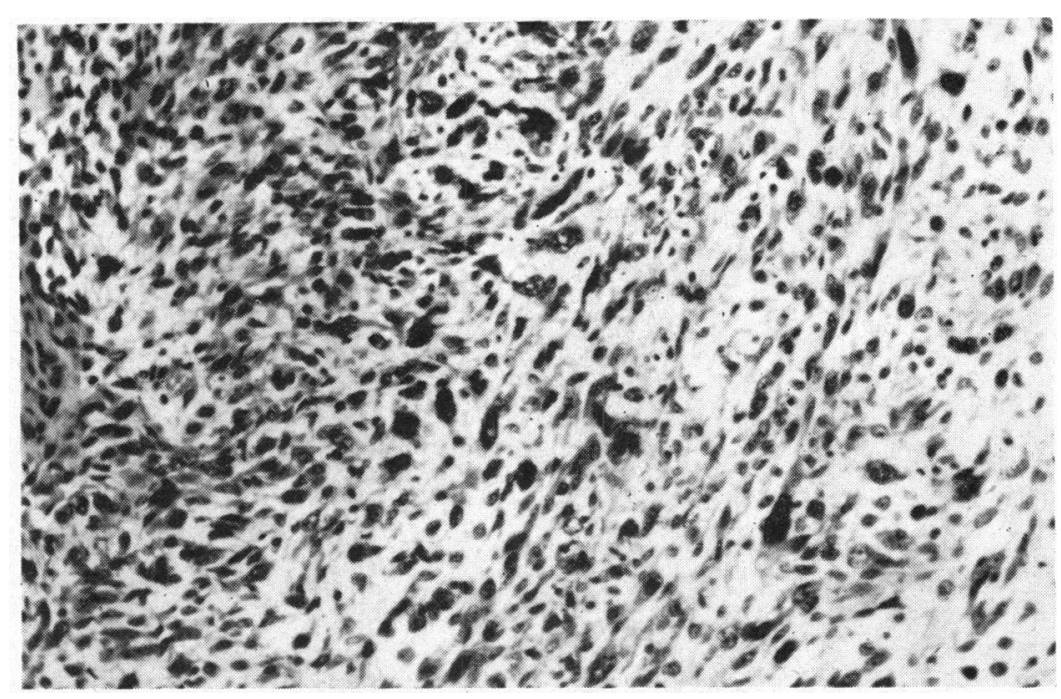

FIG. 3.-Section of retro-orbital mass to show active spindle-cell fibrosarcomatous area of the tumour. Haematoxylin and eosin, $\times 225$.

Deep coma supervened and the patient died 12 days after admission to hospital.

Autopsy showed a mass of tumour involving the right orbit and extending laterally to fill the right temporal fossa. On section, the tumour tissue was pale and necrotic and extended deep to the deep fascia, destroying the lateral wall of the orbit and invading through into the anterior cranial fossa. There was marked oedema of the brain with flattened convolutions and prominent cerebellar and tentorial pressure cones. There was a 3-cm. defect into the right parietal bone through which tumour had extended to a depth of $4 \mathrm{~cm}$. There was pressure necrosis of the right frontal lobe, but no invasion of brain tissue. There was no abnormality elsewhere in the body.

Sections of the tumour showed a pleomorphic spindle-cell sarcoma with much myxomatous degeneration, the features of a fibromyxosarcoma arising in the soft tissues immediately behind the eye (Fig. 3). There was no evidence of intra-ocular tumour; the frontal bone was invaded, but sections confirmed that the brain, though softened, was free of growth.

\section{Dose to the Original Tumour}

It was thought interesting to try and compute the gamma-ray dose received by the tumour 33 years earlier, and thanks to the kindness of Mr. D. E. A. Jones (Chief Physicist, Mount Vernon Hospital) it was possible to estimate this without gross inaccuracy.

As stated earlier, the right orbit was given three separate courses of radium between March and July, 1931. Sufficient data were unearthed from the original case notes to enable us to work out that the retina received a dose of no less than 9,250 roentgens. We have assumed that the area treated in the first and second treatment sessions-unstated in the case records-was $5.0 \times 5.5 \mathrm{~cm}$., which was the area stated in the third treatment session. We have also assumed that the centre of the retina was $1.8 \mathrm{~cm}$. deep to the anterior surface of the globe. Tissues $5 \mathrm{~mm}$. and $10 \mathrm{~mm}$. deep to the retina would have received doses of 6,900 roentgens and 6,100 roentgens respectively.

\section{Discussion}

The diagnosis of radiation-induced malignancy was suggested by the past history of intensive radium treatment of the right eye and the long time-interval. Recurrence of retinoblastoma, though possible, would have been extremely rare. Our view of the diagnosis was fortified by the presence of permanent radiation changes in the skin of the right side of the forehead and face, indicating that a high dose had 
been given. Hair growth, though not as profuse as on the left, was surprisingly normal.

Subsequent calculation showed that a very high dose of gamma rays had indeed been given to the whole of the right orbit and to all other tissues in the vicinity. In support of this, we computed that tissues $1 \mathrm{~cm}$. deep to the retina must have received no less than 6,100 roentgens. The theoretical conditions were therefore right for the development of a radiation-induced malignant tumour. Biopsies, though apparently adequate, did not help and we had to await post-mortem histology for final proof.

The original case records are unfortunately incomplete. As a baby the patient had had "bilateral ocular gliomata", but we have no description of the condition of the left eye before enucleation and no histological material from either eye. We are assuming therefore that this was an instance of bilateral retinoblastoma treated with great success by a combination of surgery and radium.

It seems very bad luck that the patient should have succumbed from a rare complication of his original treatment.

I am particularly grateful to Mr. R. Affleck Greeves for permission to use the original case notes, to Mr. D. E. A. Jones for the gamma-ray dose calculation, to Dr. Michael Bennett for the histological report and photomicrograph, to Miss N. Walker for the photographs, and to Miss P. Cragg for secretarial assistance. 